\title{
Social Stress In Relation To Social-Emotional Learning Among Adolescents
}

\author{
Priyanka Panwar \\ Research Scholar, Dept. of Human Development and Family Studies, \\ College of Community Science, Punjab Agricultural University, \\ Ludhiana, Punjab, India \\ Email: panwarp55@gmail.com \\ Seema Sharma \\ Principal Extension Scientist, \\ Dept. of Human Development and Family Studies, College of Community Science, \\ Punjab Agricultural University, Ludhiana, Punjab, India
}

\begin{abstract}
The word 'stress' nowadays has become a typical word and almost every individual at any stage, at any age of their life, experiences it. Social-emotional learning competencies are regarded as a good marker of how well adolescents adjust to their surrounding environments and these competencies aid adolescents in coping with social stress during adolescence. The objective of the study was to find out the association between social stress and social-emotional learning among adolescents. The data was collected from 500 adolescents in the age range of 13-14 years and Scale of Social Stress by Bisht (2005) was used to assess the level of social stress among adolescents. The study revealed that significantly more number of adolescents from nuclear families were at the average level of social frustration and social pressure dimensions of social stress. Adolescents from joint families significantly experienced more social pressure. Further, social-emotional learning was non-significantly positively correlated with social stress in joint families and nonsignificantly negatively correlated with social stress in nuclear families.
\end{abstract}

Keywords: Social stress, competencies, joint families, nuclear families, adolescents
Reference to this paper

should be made as follows:

Received: 15.08 .2020

Approved: 29.09.2020

Priyanka Panwar

Seema Sharma

Social Stress In Relation

To Social-Emotional

Learning Among

Adolescents

Article No. 28

RJPSS Sept. 2020,

Vol. XLV No. 2,

pp. 238-245

Online available at:

https://anubooks.com/

rjpss-2020-vol-xlv-no-2/

https://doi.org/10.31995/

rjpss.2020.v45i01.028 
RJPSS Sept. 2020 Vol. XLV No.2, ISSN: (P)0258-1701 (e)2454-3403 Impact Factor: 7.717

https://doi.org/10.31995/rjpss.2020.v45i01.028

\section{Introduction}

Humans are social beings by nature, as they classically have a deep-seated want and desire to sustain constructive social relationships (Slavich et al 2010). If anything interrupts or threatens to interrupt their relationships with others, it can result in social stress. Social stress is defined as the feelings of uneasiness or nervousness that individuals may experience in social circumstances, and the allied tendency to evade potentially stressful social circumstances (Wadman et al 2011). Social-emotional learning competencies are thought to be good indicators of how well an individual adjust to his/her surrounding environments and become accustomed to change in their social situations (Brotto 2018). This reflects how social-emotional learning competencies aid an individual in coping with social stress as, during adolescence, social stress becomes predominantly prominent as a menace to psychological well-being and social-emotional well-being (La Greca 2001). Adolescence is the most essential period of human development where an individual finds difficulty in dealing with social situations and also, Hall (1904) regarded this stage of human life as a period of "storm and stress".

A study conducted by Weare and Gray (2003) reviewed the effect of various social and emotional competence initiatives and reported that social-emotional competence resulted in improved social cohesion and social inclusion which indicates that students will have less stress in social settings with the implementation of social and emotional competence programs.

\section{Objectives of the study}

i. To study the level of social stress among adolescents belonging to joint and nuclear families.

ii. To find out the association between social stress and social-emotional learning among adolescents belonging to joint and nuclear families.

\section{Materials and Methods}

Sample: The sample of the study consisted of 500 school-going adolescents in the age group of 13-14 years studying in government schools located at Ludhiana, Punjab.

Sample selection: Eight government schools were selected using a random selection technique to comprise a sample size of 500 adolescents. The sample was 
Social Stress In Relation To Social-Emotional Learning Among Adolescents

Priyanka Panwar Seema Sharma

further distributed and selected purposively giving representation to family structure i.e. 250 adolescents from nuclear families and 250 adolescents from joint families.

Research instrument: Scale of Social Stress (SSS) from Bisht Battery of Stress Scales developed by Bisht (2005) was used to assess the level of social stress among adolescents. Each sub-scale of the battery measured four components of social stress viz. frustration, conflict, pressure, and anxiety.

Statistical analysis of data: The data analysis was completed by means of suitable statistical techniques such as frequency, percentage, arithmetic mean, standard deviation, Z-test, student's t-test, and Karl Pearson's coefficient of correlation.

\section{Results and Discussion}

\section{Assessment of social stress among adolescents as per their family structure}

The portrayal of data in the table 1 elucidates the frequency distribution of adolescents across various dimensions of social stress. The distribution of data demonstrated significant differences as per family structure at the average level of social frustration wherein the maximum number of adolescents belonging to nuclear families $(1.96 ; \mathrm{p}<0.05)$ represented this level in comparison to adolescents from joint families. Moreover, at both low level (20.40\%) and high level (12.80\%), adolescents from joint families outweighed adolescents living in nuclear families.

It was further contemplated that there were significant differences with respect to the family structure at an average level and high level of social pressure wherein at an average level, a higher proportion of adolescents from nuclear families $(5.09 ; \mathrm{p}<0.01)$ and conversely, at a high level, adolescents from joint families (5.31; $\mathrm{p}<0.01)$ were more in number as compared to their counterparts. In the low level, adolescents living in joint families $(13.60 \%)$ outnumbered adolescents living in nuclear families.

Under social conflict and social anxiety dimensions of social stress and overall social stress, non-significant differences in relation to the family structure were recorded at all the levels of the above mentioned categories. It was further illustrated that the majority of the adolescents from nuclear families were at an average level of all the three above mentioned categories viz. social conflict $(58.00 \%)$, social anxiety $(71.60 \%)$ and overall social stress $(64.40 \%)$ when compared with adolescents belonging to joint families. 
RJPSS Sept. 2020 Vol. XLV No.2, ISSN: (P)0258-1701 (e)2454-3403 Impact Factor: 7.717

https://doi.org/10.31995/rjpss.2020.v45i01.028

Table 1: Percent distribution of the adolescents as per their family structure across different dimensions of social stress

\begin{tabular}{|c|c|c|c|c|c|c|}
\hline \multirow{2}{*}{$\begin{array}{c}\text { Dimensions } \\
\text { of Social } \\
\text { Stress }\end{array}$} & \multirow[t]{2}{*}{ Levels } & \multicolumn{2}{|c|}{$\begin{array}{c}\text { Joint } \\
\text { Families } \\
\left(\mathbf{n}_{1}=\mathbf{2 5 0}\right)\end{array}$} & \multicolumn{2}{|c|}{$\begin{array}{l}\text { Nuclear } \\
\text { Families } \\
\left(n_{2}=250\right)\end{array}$} & \multirow[t]{2}{*}{$\begin{array}{c}\text { Z- } \\
\text { value }\end{array}$} \\
\hline & & $f$ & $\%$ & $f$ & $\%$ & \\
\hline \multirow{3}{*}{$\begin{array}{l}\text { Social } \\
\text { Frustration }\end{array}$} & Low & 51 & 20.40 & 35 & 14.00 & 1.89 \\
\hline & Average & 167 & 66.80 & 187 & 74.80 & $1.96^{*}$ \\
\hline & High & 32 & 12.80 & 28 & 11.20 & 0.55 \\
\hline \multirow{3}{*}{$\begin{array}{l}\text { Social } \\
\text { Conflict }\end{array}$} & Low & 77 & 30.80 & 74 & 29.60 & 0.29 \\
\hline & Average & 140 & 56.00 & 145 & 58.00 & 0.45 \\
\hline & High & 33 & 13.20 & 31 & 12.40 & 0.26 \\
\hline \multirow{3}{*}{$\begin{array}{l}\text { Social } \\
\text { Pressure }\end{array}$} & Low & 34 & 13.60 & 28 & 11.20 & 0.81 \\
\hline & Average & 144 & 57.60 & 197 & 78.80 & $5.09 * *$ \\
\hline & High & 72 & 28.80 & 25 & 10.00 & $5.31 * *$ \\
\hline \multirow{3}{*}{$\begin{array}{l}\text { Social } \\
\text { Anxiety }\end{array}$} & Low & 34 & 13.60 & 25 & 10.00 & 1.24 \\
\hline & Average & 166 & 66.40 & 179 & 71.60 & 1.25 \\
\hline & High & 50 & 20.00 & 46 & 18.40 & 0.45 \\
\hline \multirow{3}{*}{$\begin{array}{l}\text { Overall } \\
\text { Social Stress }\end{array}$} & Low & 61 & 24.40 & 48 & 19.20 & 1.40 \\
\hline & Average & 145 & 58.00 & 161 & 64.40 & 1.46 \\
\hline & High & 44 & 17.60 & 41 & 16.40 & 0.35 \\
\hline
\end{tabular}

Note: *Significant at $5 \%$ level, $* *$ Significant at $1 \%$ level

\section{Comparison of social stress among adolescents as per their family structure}

The interpretation of data shown in the table 2 illustrates the difference in the mean scores of adolescents across different dimensions of social stress with reference to family structure. Depiction of data as per family structure revealed a significant difference in the mean score of social pressure dimension of social stress (3.57; $\mathrm{p}<0.01)$ wherein adolescents living in joint families experienced more pressure in social settings (mean $=36.83$ ) when compared with their counterparts.

Furthermore, non-significant differences were noted for other dimensions of social stress as well as for overall social stress. However, the pattern of mean scores exemplified that adolescents from joint families had more mean scores for social conflict (mean $=31.04)$ and overall social stress (mean=147.19), whereas social frustration $($ mean $=43.83)$ and social anxiety $(m e a n=36.92)$ had more mean scores for adolescents living in nuclear families. Therefore, these findings pointed out that adolescents belonging to nuclear families were more socially frustrated and become anxious in social surroundings, while adolescents living in joint families tend to have more societal conflicts and encounter more stress in social situations. It is because, in joint families, there are more set customs and traditions of how to 
Social Stress In Relation To Social-Emotional Learning Among Adolescents

Priyanka Panwar Seema Sharma

socially interact with people and adolescents are so much dependent on family members to solve their problems which results in adolescents becoming more stressed in social situations. In a study conducted by Mathil (2016), it was reported that adolescents living in nuclear families are more socially adjusted than adolescents living in joint families. For this reason, adolescents residing in nuclear families faceless social stress when in social surroundings.

Table 2: Comparative mean scores $( \pm \mathrm{SD})$ of the adolescents as per their family structure across different dimensions of social stress

\begin{tabular}{|l|c|c|c|c|c|}
\hline \multirow{2}{*}{\begin{tabular}{c}
\multirow{2}{*}{$\begin{array}{c}\text { Dimensions of Social } \\
\text { Stress }\end{array}$} \\
\cline { 2 - 6 }
\end{tabular}} & \multicolumn{2}{|c|}{$\begin{array}{c}\text { Joint Families } \\
\left(\mathbf{n}_{\mathbf{1}}=\mathbf{2 5 0}\right)\end{array}$} & \multicolumn{2}{c|}{$\begin{array}{c}\text { Nuclear Families } \\
\left(\mathbf{n}_{2}=\mathbf{2 5 0}\right)\end{array}$} & \multirow{2}{*}{ t-value } \\
\cline { 2 - 6 } Social Frustration & 42.98 & 15.57 & 43.83 & 16.70 & 0.58 \\
\hline Social Conflict & 31.04 & 13.03 & 30.91 & 13.35 & 0.11 \\
\hline Social Pressure & 36.83 & 9.67 & 33.84 & 9.02 & $3.57 * *$ \\
\hline Social Anxiety & 36.46 & 11.48 & 36.92 & 12.23 & 0.43 \\
\hline Overall Social Stress & 147.19 & 42.78 & 145.27 & 38.70 & 0.52 \\
\hline
\end{tabular}

Note: **Significant at $1 \%$ level

\section{Correlation between different dimensions of social-emotional learning and social stress among adolescents as per their family structure}

The depiction of data in the table 3 brings to light the correlation analysis between five dimensions of social-emotional learning and four dimensions of social stress among adolescents with reference to family structure. The examination of data among adolescents from joint families revealed that the self-awareness dimension was significantly positively correlated with social pressure $(\mathrm{r}=0.15$; $\mathrm{p}<0.05)$ and social anxiety $(\mathrm{r}=0.16 ; \mathrm{p}<0.01)$ dimensions of social stress. So, these findings indicate that when adolescents living in joint families were only self-aware then, they were likely to encounter pressure and anxiety in social settings. Further, other dimensions of social-emotional learning had a non-significant association with all the dimensions of social stress.

Further probe into data highlighted that overall social-emotional learning was significantly positively correlated with social anxiety $(\mathrm{r}=0.13 ; \mathrm{p}<0.05)$. Thus, this suggests that adolescents from joint families, who had good social-emotional learning competencies, were apt to become anxious in social interactions and social 
RJPSS Sept. 2020 Vol. XLV No.2, ISSN: (P)0258-1701 (e)2454-3403 Impact Factor: 7.717

https://doi.org/10.31995/rjpss.2020.v45i01.028

gatherings. Also, overall social-emotional learning and its dimensions had nonsignificant relation with overall social stress.

Further interpretation of data among adolescents belonging to nuclear families pointed out that social awareness dimension was significantly negatively correlated with social frustration $(\mathrm{r}=-0.20 ; \mathrm{p}<0.01)$ and social anxiety $(\mathrm{r}=-0.13$; $\mathrm{p}<0.05$ ) dimensions of social stress. Therefore, it could be inferred that adolescents living in nuclear families, who were socially aware, were perceived to experience less frustration and anxiety in different social surroundings. Furthermore, the relationship management dimension had a significant negative association with social anxiety $(\mathrm{r}=-0.12 ; \mathrm{p}<0.05)$. So, this implies that adolescents from nuclear families, who maintained a good relationship with people, were less likely to become anxious in social situations. However, other dimensions and overall social-emotional learning had a non-significant association with overall social stress and its dimensions.

\section{Conclusion}

It is noticeable from the findings of the research that significantly more number of adolescents from nuclear families were noticed at an average level of social frustration and social pressure dimensions of social stress. The mean difference indicated that adolescents from joint families significantly experienced more social pressure. It was further revealed that in joint families, the self-awareness dimension of social-emotional learning had a significant positive correlation with the social pressure dimension of social stress. Also, the self-awareness dimension and overall social-emotional learning were found to be significantly positively correlated with the social anxiety dimension of social stress. Furthermore, the social awareness dimension was significantly negatively related to the social frustration dimension of social stress in adolescents from nuclear families. Also, social awareness and relationship management dimensions had a significant negative correlation with the social anxiety dimension of social stress in nuclear families. Further, social-emotional learning was non-significantly positively correlated with overall social stress in adolescents from joint families. Also, social-emotional learning was noted to be non-significantly negatively correlated with overall social stress in adolescents from nuclear families. Thus, this research emphasized that feeling of stress among adolescents from both joint and nuclear families should not be disregarded and neglected; however, it has to be appropriately intervened, to evade a larger destruction and also, for good development in all the areas of growth for adolescents. 
Social Stress In Relation To Social-Emotional Learning Among Adolescents

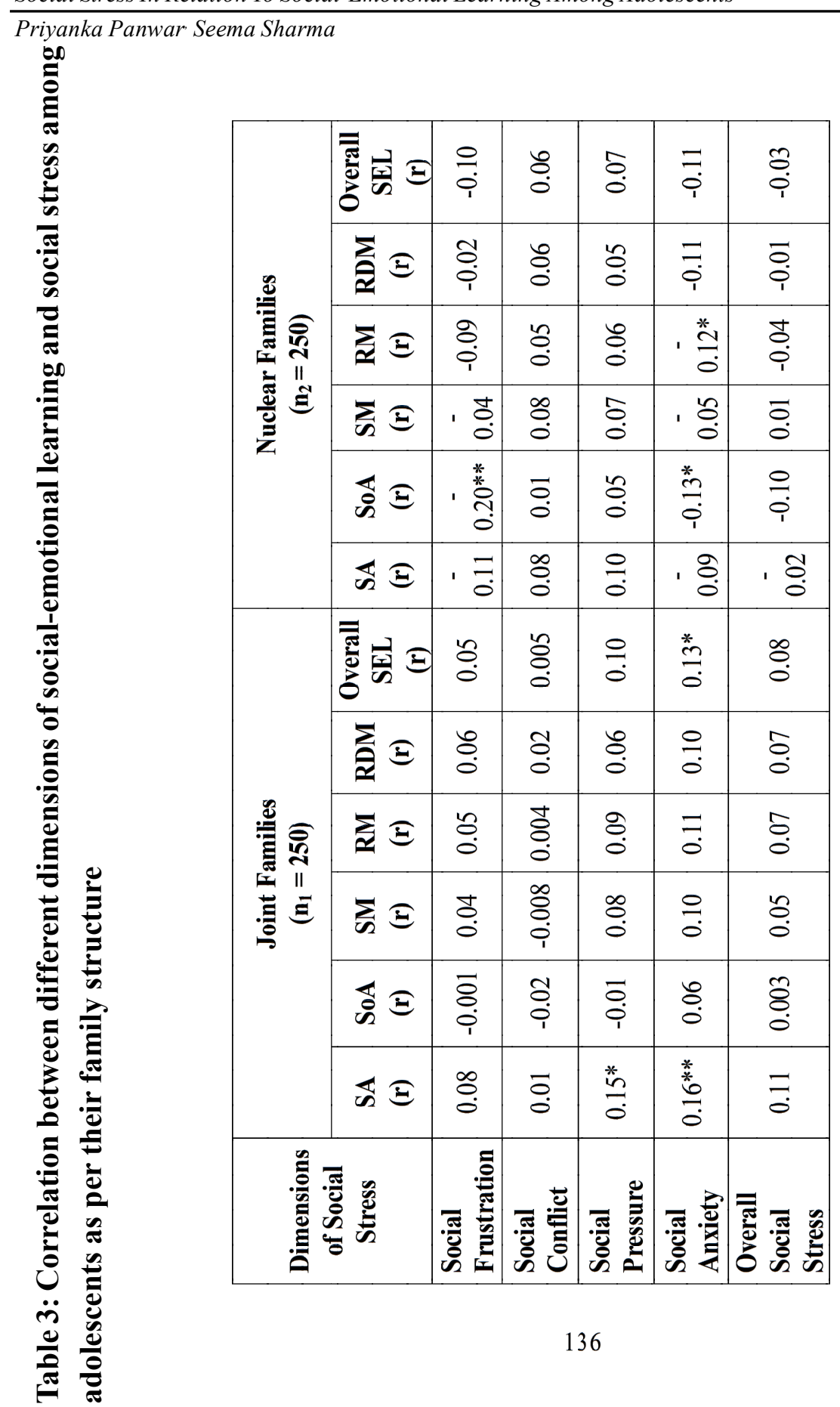


RJPSS Sept. 2020 Vol. XLV No.2, ISSN: (P)0258-1701 (e)2454-3403 Impact Factor: 7.717

https://doi.org/10.31995/rjpss.2020.v45i01.028

\section{References}

1. Bisht, A.R. 2005. Manual for Bisht Battery of Stress Scales. Agra: National Psychological Corporation.

2. Brotto, G. 2018. The Future of Education Depends on Social Emotional Learning: Here's Why. Pp. 1-2. Unites States: EdSurge Inc.

3. Hall, G.S. 1904. Adolescence: In Psychology and Its Relation to Physiology, Anthropology, Sociology, Sex, Crime, Religion, and Education. Pp. 317-19. D. New York: Appleton and Company.

4. La Greca, A.M. 2001. Friends or foes? Peer influences on anxiety among children and adolescents. In: Silverman, WKAT.; Treffers, PDA., editors. Anxiety disorders in children and adolescents: research, assessment, and intervention. Cambridge: Cambridge University Press.

5. Mathil, D. (2016). Social adjustment of adolescents in relation to their family structure. International Journal of Advance Research and Innovative Ideas in Education, 2(6), 1817-1824.

6. Slavich, G.M., O'Donovan, A., Epel, E.S., and Kemeny, M.E. (2010). Black sheep get the blues: a psychobiological model of social rejection and depression. Neuroscience and Biobehavioral Reviews, 35(1), 39-45.

7. Wadman, R., Durkin, K., and Conti-Ramsden, G. (2011). Social stress in young people with specific language impairment. Journal of Adolescence, 34 (3), 421431.

8. Weare, K., and Gray, G. 2003. What works in developing children's emotional and social competence and well-being? Pp. 6-33. DfES Research Report 456. Southampton: The Health Education Unit, Research and Graduate School of Education, Southampton. 